\title{
New Aspects in the Management of Hypertension in Patients with Chronic Kidney Disease not on Renal Replacement Therapy
}

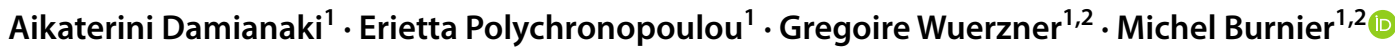

Received: 3 November 2021 / Accepted: 30 November 2021 / Published online: 15 December 2021

(c) The Author(s) 2021

\begin{abstract}
With chronic kidney disease (CKD) being a global arising health problem, strategies for delaying kidney disease progression and reducing the high cardiovascular risk inherent to CKD, are the main objectives of the actual management of patients with kidney diseases. In these patients, the control of arterial hypertension is essential, as high blood pressure (BP) is a strong determinant of worst cardiovascular and renal outcomes. Achieving target blood pressures recommended by international guidelines is mandatory and often demands a multiple levels management, including several pharmacological and lifestyle measures. Even in the presence of adequate BP control, the residual cardiovascular risk remains high. In this respect, the recent demonstration that novel agents such as sodium glucose transporter 2 (SGLT2) inhibitors or the new non-steroidal mineralocorticoid antagonist finerenone can retard the progression of kidney diseases and reduce cardiovascular mortality on top of standard of care treatment with renin-angiotensin system inhibitors represent enormous progresses. These studies also demonstrate that cardiovascular and renal protection can be obtained beyond blood pressure control. Other promising novelties are still to come such as renal denervation and endothelin receptor antagonists in the setting of diabetic and non-diabetic kidney diseases. In the present review, we shall discuss the classic and the new aspects for the management of hypertension in CKD, integrating the new data from recent clinical studies.
\end{abstract}

Keywords Hypertension - Chronic kidney disease - Blockers of the renin-angiotensin - Diuretics - Calcium antagonists . SGLT2 inhibitors $\cdot$ Finerenone $\cdot$ Endothelin antagonists

\section{Introduction}

Chronic kidney disease (CKD) is a global health problem, representing the third fastest growing cause of death globally, with an estimated prevalence of $8-16 \%$ in occidental countries $[1,2]$. CKD is defined by the presence of kidney damage or decreased kidney function with an estimated glomerular filtration rate (eGFR) $<60 \mathrm{~mL} / \mathrm{min} / 1.73 \mathrm{~m}^{2}$ for at least 3 months irrespective of the cause. Kidney damage refers to pathologic abnormalities (such as hematuria or structural abnormalities) or urine albumin-to-creatinine ratio (UACR) $>30 \mathrm{mg} / \mathrm{g}$ in spot urine specimens. According to the KDIGO guidelines, CKD is classified in five stages

Michel Burnier

michel.burnier@chuv.ch

1 Service of Nephrology and Hypertension, University Hospital, Rue du Bugnon 17, 1011 Lausanne, Switzerland

2 Hypertension Research Foundation, Saint-Légier, Switzerland according to the level of GFR (G1 to G5) and three categories according to the absence or presence of albuminuria (A1-A3) [3].

The reasons why the incidence and prevalence of advanced CKD is rising, include aging population, low detection rate, poor adherence and increasing prevalence of hypertension and type 2 diabetes [4-6]. Indeed, hypertension and diabetes remain two of the most important causes of CKD and with their increasing prevalence, it is projected that CKD prevalence in adults over 30-years-old will rise to $16.7 \%$ in 2030 [7]. However, a recently published Canadian study suggests that the current CKD definition that does not consider age-related eGFR decline, may inflate the burden of CKD by classifying many elderly people with normal kidney aging as having a disease [8]

Cardiovascular disease (CVD) is the leading cause of morbidity and death among CKD patients. According to 2018 ESC/ESH hypertension guidelines and 2021 ESC guidelines on cardiovascular disease prevention, patients suffering from CKD (G3-5 irrespectively of albuminuria 
and G1-2 with A3) are automatically considered to be at high-very high 10-year cardiovascular (CV) risk $[9,10]$. Even after correction for classical CV risk factors (as diabetes, hypertension) in non-dialyzed CKD patients, the impact of CKD on CV risk still remains of high importance, with the probability of developing cardiovascular disease increasing linearly as kidney function deteriorates with an eGFR below $60-75 \mathrm{ml} / \mathrm{min} / 1.73 \mathrm{~m}^{2}[11,12]$. Hence, patients with advanced CKD are expected to die from any cardiovascular event before reaching end-stage kidney disease (ESKD). In line with this, several metaanalyses have demonstrated the association of lower eGFR and higher albuminuria with cardiovascular disease as being risk factors for all-cause and cardiovascular mortality in the general population and in high risk populations, independent of the traditional CV risk factors [13-15].

\section{Blood Pressure Targets in CKD}

Blood pressure (BP) targets in patients with CKD have been a matter of debate for years. The disagreement has been imprinted in recent international guidelines [2018 European Society Hypertension, American College of Cardiology-American Heart Association (ACC/AHA), International Society of Hypertension (ISH), ESC cardiovascular disease prevention guidelines] juggling from targets $<140 / 90 \mathrm{mmHg}$ to $<130 / 80 \mathrm{mmHg}$ and most recently $<120 / 80 \mathrm{mmHg}$ as proposed by the new KDIGO guidelines (Fig. 1) [9, 10, 16-18]. Interestingly, the 2021 KDIGO guidelines for management of BP in CKD patients not receiving dialysis have been revised and propose a target SBP of $<120 \mathrm{mmHg}$, if tolerated with the indispensable prerequisite that standardized office measurement technique be employed [19]. The recommendation is considered weak (Grade 2b) [16].

\begin{tabular}{|c|c|c|c|c|}
\hline Society & General population & Diabetes & CKD & First line treatment \\
\hline \multicolumn{5}{|c|}{$\begin{array}{l}\text { Apply lifestyle interventions: smoking cessation, reduce salt intake }<5-6 \mathrm{gr} / \text { day, alcohol moderation, weight control, regular exercise } \\
\text { (additionally, stress reduction and avoid air pollution**) }\end{array}$} \\
\hline ACC/AHA 2017 & $<130 / 80 \mathrm{mmHg}$ & $<130 / 80 \mathrm{mmHg}$ & $<130 / 80 \mathrm{mmHg}$ & $\begin{array}{l}\text { Diuretics, CCBs or RASi } \\
1^{\text {st }} \text { line: RASi if CKD stage G }>3 \text { or } \\
\text { stage G1-2 / A3 } \\
\text { Consideration of 2-drug strategy } \\
\text { for stage } 2\end{array}$ \\
\hline ESC/ESH 2018 & $\begin{array}{l}<65 y \mathrm{ys}:<130-120 / 80-70 \mathrm{mmHg} \\
\geq 65 y \mathrm{ys}:<140-130 / 80-70 \mathrm{mmHg}\end{array}$ & $\begin{array}{l}<65 y r s: \\
<130-120 / 80-70 \mathrm{mmHg} \\
\geq 65 y r s: \\
<140-130 / 80-70 \mathrm{mmHg}\end{array}$ & $<140-130 / 80-70 \mathrm{mmHg}$ & $\begin{array}{l}\text { RASi+CCB or RASi+diuretic } \\
\text { (or loop diuretic) }\end{array}$ \\
\hline ISH $2020 * *$ & $\begin{array}{l}<65 y r s:<130 / 80 \mathrm{mmHg} \text {, } \\
\geq 65 y \mathrm{ys}:<140 / 90 \text { but individualize in the } \\
\text { elderly based on frailty }\end{array}$ & $<130 / 80 \mathrm{mmHg}$ & $<130 / 80 \mathrm{mmHg}$ & $\begin{array}{l}\text { RASi+CCB or } \\
\text { CCB+diuretic in Black patients }\end{array}$ \\
\hline ESC 2021 & $\begin{array}{l}<140 / 90 \mathrm{mmHg} \text {, tailored to age and } \\
\text { specific comorbidities } \\
18-69 \mathrm{yrs} \text { : SBP lowered to } 120-130 \\
\mathrm{mmHg} \\
\geq 70 \mathrm{yrs} \text { : SBP target }<140 \text { down to } 130 \\
\mathrm{mmHg} \text { if tolerated } \\
\mathrm{DBP}<80 \mathrm{mmHg}\end{array}$ & $\begin{array}{l}<140 \text { to } 130 \mathrm{mmHg} \\
\text { if tolerated } \\
\text { Intensify goals to }<130 \mathrm{mmHg} \text { if } \\
\text { ESC CVD risk calculator high } \\
\text { DBP }<80 \mathrm{mmHg}\end{array}$ & $\begin{array}{l}<140 / 90 \mathrm{mmHg} \\
\text { Targets tailored to age and } \\
\text { specific comorbidities }\end{array}$ & $\begin{array}{l}\text { RASi+CCB or RASi+diuretic } \\
\text { (or loop diuretic) + } \\
\text { SGLT2i as part of first line } \\
\text { antihyperglycemic treatment } \\
\text { regimen for DM and eGFR } \geq \\
30 \mathrm{ml} / \mathrm{min} \\
1^{\text {st }} \text { line: RASi if DM, HTA and } \\
\text { albuminuria }\end{array}$ \\
\hline KDIGO 2021 & & & $\mathrm{SBP}<120 \mathrm{mmHg}$ & $\begin{array}{l}\text { 1rst line: RASi if CKD G1-4 and } \\
\text { albuminuria A2-3 } \\
\text { If combination needed: RASi+CCB } \\
\text { or RASi+diuretic (or loop diuretic) }\end{array}$ \\
\hline
\end{tabular}

Fig. 1 A summary of recent blood pressure targets recommendations by international societies and recommended first line antihypertensive treatments (from references [9, 10, 16-19]) 
At this stage, it is important to remember that the measurement of BP in Systolic Blood Pressure Intervention Trial (SPRINT), which is the basis for the ACC/AHA and KDIGO 2021 recommendations, was unattended and that $120 \mathrm{mmHg}$ has been shown to correspond to $135 \mathrm{mmHg}$ when measured in the practitioner's office [20,21]. Consequently, a true threshold of $<120 \mathrm{mmHg}$ would be considered very strict for the real clinical setting where the white coat effect is of importance. Additionally, evidence for applying BP target $<120 \mathrm{mmHg}$ especially in those with advanced CKD (stages $4-5$ ), with diabetes, aged $>90$ years old and $<50$ years old, the very frail, with very low diastolic BP, or with "white coat" or severe hypertension are limited in KDIGO guidelines. Thus, adopting this threshold for all CKD patients seems to be quite uncertain in term of benefits outweighing harms and less feasible considering that less than $30 \%$ of hypertensive patients achieve the $<130 / 80 \mathrm{mmHg}$ in the real setting [22]. Finally, in clinical practice, achieving the proposed optimal BP $<120 \mathrm{mmHg}$ means adding medication in a population having already a high pill burden, with the risk of promoting sub-optimal adherence or sub-optimal collaboration with the patients, in addition to increasing the risk of hypotensive episodes.

Taken together, the diagnosis and management of hypertension in CKD should be individualized. Lowering BP to at least $<140 / 90 \mathrm{mmHg}$ should be adopted in all patients. So far, the threshold of $<130 \mathrm{mmHg}$ showing the best combination for $\mathrm{CV}$ prevention and safety, should be considered especially in young or proteinuric patients.

\section{Management of Hypertension in CKD}

\section{1) Consider the $24 \mathrm{~h}$ blood pressure profile}

While the diagnosis and management of arterial hypertension are based on standardized office BP measurements, patients with CKD are prone to abnormal BP patterns revealed when BP is measured out-of-office using ambulatory BP monitoring (ABPM). The main observation is that both decreased eGFR and proteinuria are associated with elevated nocturnal BP and a nondipping pattern [23-26]. An increased sympathetic tone, salt-sensitivity and volume overload, sleep disorders are some of the mechanisms responsible for the increase in nighttime BP values observed in CKD patients [27].

In addition, masked hypertension due mainly to high nocturnal BP is also frequent in CKD, so implementation of ABPM guidance for diagnosis and treatment of arterial hypertension in this population seems important [28-31]. Studies exploring whether nocturnal hypertension and non-dipping are associated with CKD progression, have shown an increased risk for renal outcomes when nighttime BP is elevated [32-34]. Therefore, besides lowering office BP to the recommended targets, controlling BP during the $24 \mathrm{~h}$ of the day, and in particular during nighttime, is of great importance in the management of CKD patients to lower their CV risk and retard the progression of renal disease.

2) Implement lifestyle recommendations

Lifestyle changes are recommended by all hypertension guidelines and are considered the initial step for BP control even among CKD patients. Thus, smoking cessation, weight control, limitation of alcohol consumption and exercising should be proposed to all CKD patients. Whenever necessary, changes in diet should also be implemented. Thus, in patients with CKD a salt intake of 5-6 g per day (with the exception the patients with salt wasting nephropathy), is proposed by most if not all international guidelines. Indeed, CKD patients present a salt sensitive BP phenotype, which confers to an excess $\mathrm{CV}$ risk and is associated with a faster disease progression $[35,36]$. Additionally, a high salt intake increases urinary albumin excretion, another marker of poor renal outcome [37]. Today, the potential benefits of restricting salt intake are still discussed. Nevertheless, several studies and some meta-analyses have suggested that lowering sodium intake delays renal disease progression [3840]. Recently, an open-label, cluster-randomized trial, the SSaSS study, including older adults with a history of stroke or high BP, has demonstrated prospectively the benefits of reducing sodium and increasing potassium intake in terms of CV morbidity [41, 42]. Importantly, the study also included individuals with CKD and the intervention was estimated to be net lifesaving in this subgroup as well, with three averted deaths from reduction in systolic BP for each death related to hyperkaliemia. So far, no evidence of detrimental effect of salt reduction in $\mathrm{CKD}$ patients has been reported and increasing potassium intake may actually be beneficial in the early CKD stages (1 and 2). However, one should be cautious in using potassium-containing salts in advanced CKD. Finally, a low-sodium intake in combination of angiotensin-converting enzyme inhibitor (ACEi) and angiotensin 2 receptor blocker (ARB) -commonly used in CKD patients- has been shown to enhance the beneficial effects of these medications on kidney and CV outcomes [43].

3) Prescribe an antihypertensive drug therapy

Today, prescribing a blocker of the renin-angiotensin system (RAS) remains the first recommended step in the medical treatment of CKD patients (Fig. 1) [10]. Indeed, both ACEi and ARBs have demonstrated a renoprotective effect due to their antihypertensive and antiproteinuric effects. Accordingly, the recent KDIGO 2021 guidelines recommend, with a strong class evidence $1(\mathrm{~B})$, to start with RAS inhibitors (RASi) in hypertensive CKD 
patients with stage G1-G4 and marked albuminuria with or without diabetes [44-47].

Whether the RASi provide cardiorenal benefits in non-diabetic CKD patients with less degree or no albuminuria remains an open question in the absence of randomized control trials (RCT). RAS blockade is often associated with an acute rise in serum creatinine. Recent data from general population studies in UK have suggested that the acute decline in GFR observed on starting treatment with a RAS inhibitor is associated with kidney and cardiac risks in a "dose-response" relation, with no distinct cutoff at a $30 \%$ increase in serum creatinine level [48]

Current evidence for the use of RASi in patients with advanced CKD remain controversial. Because the clinical benefits are not well demonstrated and the risk of hyperkaliemia and aggravation of renal function are important, many physicians hesitate to prescribe RAS inhibitors to these patients and eventually discontinue RAS blockers [49, 50]. There is now increasing evidence that discontinuation of RAS blockers is associated with a higher risk of all-cause mortality, major adverse events and renal replacement therapy as reported recently in the ACEi-STOP study [51, 52].

Thus, today's recommendation would be to maintain RAS blockade in advanced CKD unless patients develop severe hyperkalemia, metabolic acidosis or aggravate markedly their renal function. The availability of new well tolerated potassium binders to control hyperkaliemia, such as patiromer or sodium zirconium, enable now to maintain RASi as shown in patients with diabetic nephropathy $[53,54]$

Whether there are relevant differences between ACEi and ARBs in terms of efficacy and safety has been analyzed several times with contrasting answers [55-57]. Chen et al. recently examined the issue again in a large meta-analysis. They concluded that both classes have same efficiency- and safety-profile with the ARBs providing a lower risk for angioedema, acute pancreatitis, cough and gastrointestinal bleeding [58].

Target BPs are difficult to obtain in CKD patients and likelihood to control BP with a monotherapy is low. Therefore, ESC/ESH guidelines recommend to start drug therapy with a single pill combination of a RAS blocker and either a dihydropyridine calcium channel blocker (CCB) or a diuretic. In more advanced CKD, however, a triple combination will be necessary to achieve the defined targets. The ACCOMPLISH trial compared the benefits of combining an ACEi + amlodipine versus ACEi + hydrochlorothiazide (HCTZ) in hypertensive patients with high risk (including CKD) and found a lower risk for CKD progression when the ACEi was associated with amlodipine [59, 60].
Nevertheless, diuretics are necessary in CKD to achieve an euvolemic status, especially in advanced stages. Indeed, fluid overload, common in CKD, is considered a remarkable barrier in $\mathrm{BP}$ control and is an independent risk factor for CVD [61]. Thiazide diuretics have a blunted efficacy when the GFR falls below $30 \mathrm{ml} / \mathrm{min} / 1.73 \mathrm{~m}^{2}$, with the exception of chlorthalidone, metolazone and indapamide. Current guidelines propose switching to loop diuretics when patients reach stage G4 On the other hand, combining furosemide and HCTZ has been shown to provide a synergistic effect even in advanced CKD [62]. Importantly, data extrapolation of trials suggesting a greater potency of chlorthalidone over HCTZ due to longest duration effect and its effectiveness in reducing $\mathrm{CV}$ events and mortality in general population, makes the use of chlorthalidone an attractive alternative option in patients with CKD [18, 63].

The CLICK trial, a double-blind phase II RCT, including patients with poorly controlled HTA and a mean eGFR $23.2 \mathrm{ml} / \mathrm{min} / 1.73 \mathrm{~m}^{2}$ is ongoing and will provide further evidence on the potential benefits of chlorthalidone in shrinking extracellular fluid volume and in reducing albuminuria, providing in parallel a target organ protection in patients with advanced CKD[64]. Finally, attention should be given in patients with polycystic kidney disease where diuretics can promote cyst growth [65].

Regarding beta-blockers, their use in CKD, although not as first line treatment, is based on the upregulation of sympathetic nervous system seen in CKD, which in turn confers an increased risk of $\mathrm{CV}$ events and renal disease progression [66]. Their indications are majorly restricted to heart failure, arrhythmia, hypertrophic cardiomyopathy or coronary heart disease, comorbidities often seen in patients with CKD [67].

\section{4) Adding an aldosterone antagonist}

Steroidal mineralocorticoid receptor (MR) antagonists e.g. aldactone or eplerenone, lower BP and proteinuria. They are also the most effective add-on drug treatment in resistant hypertension, on top of a triple therapy with RASi, CCB and diuretic [68]. Given the detrimental effects of aldosterone and MR activation, via mechanisms involving oxidative stress, inflammation, and fibrosis, occurring in both heart and kidneys, the efficacy of classic steroidal MR antagonists in delaying the progression of CKD was examined and confirmed in diabetic or non-diabetic nephropathies [69-73].

However, the main limitation of aldosterone antagonists in general, and particularly in advanced CKD, is the risk of hyperkalemia especially when prescribed on top of RASi. However, the AMBER trial conducted in patients with resistant HTA and an eGFR of $25-45 \mathrm{ml} / \mathrm{min} / 1.73 \mathrm{~m}^{2}$ has pointed out that combining spironolactone with the potassium binder 
patiromer permits the continuation of the MR antagonist in this population [74]. Evidently, a close laboratory follow-up of renal function and serum potassium remains necessary whenever aldosterone antagonists are prescribed to CKD patients.

Very recently, finerenone, a novel selective non-steroidal MR antagonist with greater selectivity than spironolactone, and a better affinity than eplerenone, has been approved by the FDA to reduce the risk of kidney function decline and $\mathrm{CV}$ events in adults with CKD associated with type 2 diabetes, based on the findings of the FIDELIO-DKD and FIGARO-DKD studies [75], 76.

The results of these two large Phase III trials showed that finerenone reduces CV events by $14 \%$ and renal disease progression by $18 \%$ in diabetic patients with CKD stage 3 and 4 and moderately-to severely increased albuminuria or with CKD stage $\mathrm{G} 2$ and severely increased proteinuria (FIDELIO-DKD) after a median follow-up of 2.6 years [75, 77] . Hyperkalemia was more frequent with finerenone than placebo, with a serum potassium increase by $\sim 0.2 \mathrm{mmol} / \mathrm{l}$. Permanent discontinuation due to hyperkalemia affected only $2.3 \%$ on the finerenone arm versus $0.9 \%$ on the placebo arm. In FIGARO-CKD, which included 7347 patients with an eGFR between 25 and $90 \mathrm{ml} / \mathrm{min} / 1.73 \mathrm{~m}^{2}$, moderately elevated albuminuria (UACR between $30-300 \mathrm{mg} / \mathrm{g}$ ) or severe albuminuria (UACR $300-5000 \mathrm{mg} / \mathrm{g}$ ) and an eGFR $>60 \mathrm{ml} / \mathrm{min} / 1.73 \mathrm{~m}^{2}$, finerenone reduced the incidence of $\mathrm{CV}$ events by $13 \%$, mainly hospitalizations due to heart failure $(-29 \%)$, and decreased CKD progression [76]. Interestingly, the magnitude of cardio-renal benefits of finerenone could not be explained by its effect on BP, as the changes reported in mean systolic BP were modest. Moreover, the effects of finerenone was independent of baseline systolic $\mathrm{BP}(<138.33 \mathrm{mmHg}$ vs $>138.33 \mathrm{mmHg})$. The incidence of hyperkalemia-related discontinuation in the finerenone arm of FIGARO-CKD was $1.2 \%$ compared to $0.4 \%$ for placebo.

A combined analysis of these two large studies, the FIDELITY program, demonstrated that heart composite outcomes were reduced by $14 \%$ with finerenone $(\mathrm{p}=0.0018)$. Similarly, renal composite outcomes (time to kidney failure, a sustained $\geq 57 \%$ decrease in eGFR from baseline, or renal death) were reduced by $23 \%$ with finerenone $(\mathrm{p}=0.0002)$. Overall, the placebo-corrected reduction of mean systolic BP was $-3.7 \mathrm{mmHg}$ at 4 months and the incidence of hyperkalemia was $14 \%$ in the finerenone groups versus $6.9 \%$ in the placebo group.

While the cardio-renal benefits of finerenone were confirmed in this high-risk population being already well treated on the ideal standard-of-care treatment, it is obvious that a large number of diabetic patients with CKD of stages 1-4 and albuminuria from $30-5000 \mathrm{mg} / \mathrm{g}$ might also profit of adding finerenone to their treatment. The impact of finerenone on the incidence of hyperkalemia appeared to be modest in these 2 trials. However, one should remember that the risk may be greater once the drug is used in the real word setting, as demonstrate previous with spironolactone [78].

Finally, esaxerenone, another novel non-steroidal MR blocker, already approved in Japan for hypertension treatment, seems also having promising BP and albuminuria lowering effects as monotherapy or add-on treatment in hypertensive patients with moderate kidney dysfunction and albuminuria with and without diabetes [79-81].

\section{New Therapeutic Approaches for Diabetic and Non-diabetic Nephropathies}

1) New antidiabetic agents and cardiovascular and renal protection

The multiple properties of the new classes of glucose-lowering medications, such as sodium-glucose transporter 2 inhibitors (SGLT2i) and GLP1 receptor agonists, intensified the research for their implementation in the setting of the management of diabetic and non-diabetic kidney diseases.

Thus, in addition to lowering blood glucose, increasing glycosuria, SGLT2i have been shown to reduce glomerular hyperfiltration and to lower BP, plasma uric acid levels and body weight. The BP reduction was nicely illustrated in a global analysis of patients with type 2 diabetes and hypertension receiving empagliflozin. This analysis demonstrated that the antihypertensive effect of empagliflozin was present irrespectively of the use of diuretics and ACEi [82]. In diabetic kidney disease (stages 3b-4), dapagliflozin led to important decreases in albuminuria and BP [83]. A recent meta- analysis shows that SGLT2i induce an average reduction of systolic/ diastolic $\mathrm{BP}$ of 3.6/1.7 mmHg using 24-h ambulatory BP monitoring, figures that are comparable with the effect of a low dose of hydrochlorothiazide [84].

In the DAPA-CKD trial, prematurely stopped due to overwhelming efficacy, 4304 diabetic and non-diabetic CKD patients with eGFR of $25-75 \mathrm{ml} / \mathrm{min} / 1.73 \mathrm{~m}^{2}$ and albuminuria of $200-5000 \mathrm{mg} / \mathrm{g}$ were included [85]. The results showed that dapagliflozin, on top of RASi, reduced by $39 \%$ the primary composite outcome (sustained $>50 \%$ eGFR decline, ESRD, renal or CV death) and by $29 \%$ and $31 \%$ the secondary outcomes (CV death or heart failure hospitalization and the all-cause mortality respectively). In this study, the beneficial effects were independent of BP lowering.

Currently, the use of SGLT2 $\mathrm{i}$ is approved in patients with CKD regardless the presence of diabetes due to the proven benefits in delaying CKD disease and cardiac benefits. 
Regarding GLP-1 receptor agonists, an important reduction of $\mathrm{CV}$ mortality in type 2 diabetes and a lower incidence of microalbuminuria have been demonstrated but the mechanisms of these beneficial effects remain poorly explained [86-89]. However, so far results on hard renal points are still missing with this class of drugs. Therefore, GLP1 agonists remain a second line option for patients with diabetic kidney disease after SGLT2i [88, 90].

2) Endothelin receptor antagonists:

Several exploratory studies have suggested that endothelin (ET) receptor antagonists may be useful to lower BP and to reduce albuminuria in hypertension and in type 2 diabetes [91]. Indeed, endothelin-1 binds to ET-receptors A and B expressed in different nephron segments, with the first eliciting oxidative stress, vasoconstriction, inflammation, podocyte activation etc. and the latter the opposite effects [92, 93]. Intrarenal ET-1 regulates fluid volume with both receptors presenting natriuretic effects [94]. In CKD, there is an overproduction of ET-1 leading to albuminuria, stimulation of angiotensin II production, increased efferent vascular tone and finally glomerular hyperfiltration and HTA. Thus, targeting these hemodynamic and non-hemodynamic pathways could potentially apply in diabetic in non-diabetic CKD on top of RASi [95, 96].

Several phase II/III studies were conducted with various antagonists focusing mainly on diabetic nephropathy and the ability of this drug class to decrease proteinuria and eventually retard kidney disease progression. Positive results came from the use of sitaxsentan, atrasentan, avosentan and sparsentan with significant proteinuria reductions observed when compared to RAS blockers or on top of RAS inhibitors with more or less significant reductions in BP [97-99]. In the SONAR study, which was prematurely stopped, atrasentan decreased importantly ACR and BP and the risk for the composite primary outcome (doubling of serum creatinine, ESRD assessed with confirmed eGFR $<15 \mathrm{~mL} / \mathrm{min} / 1.73 \mathrm{~m}^{2}$ or death from kidney failure) by $35 \%$ compared to placebo in DKD patients already on RASi [100]. However, it increased heart failure rates. Indeed, important side effects such as decreases in hemoglobin and fluid retention/edema have been reported with several but not all endothelin antagonists. In several occasions, volume overload was the main reason to interrupt the clinical development of the endothelin antagonist. Indeed, these side effects may be deleterious for patients with CKD and co-existing heart failure [101, 102]. An ongoing phase 3 study is actually testing the nephroprotective effect of sparsentan (which did not cause fluid retention in phase 2) in IgA nephropathy and in patients with focal segmental glomerulosclerosis [103, 104].

\section{3) Device based hypertension treatment}

Last but not least, considering the central role of the kidney and of the sympathetic nervous system in the development and maintenance of hypertension, several interventional approaches have been developed, the most advanced one being renal denervation [105]. The first studies were conducted in patients whose BP was difficult to control and apparently resistant to at least, a triple therapy. [10, 106-108]. In this setting, CKD patients were of course part of the target populations. Later on, studies were conducted in untreated hypertensive patients in order to avoid any interference of changes in drug therapies when assessing the efficacy of renal denervation.

Initial studies performed with the first generation of devices failed to show significant effects on office and $24 \mathrm{~h}$ BP when compared to a sham procedure, although safety was confirmed. With the development of a second generation of radiofrequency or ultrasound based RDN and improvements in the procedure, significant short and midterm reductions in BP were observed and safety was always confirmed [109-112]. Globally, the antihypertensive effect is comparable to the administration of a single antihypertensive drug. The longest follow-up patients treated with RDN comes from the Global Symplicity Registry, with 687 patients having CKD stages 3a-b with $24 \mathrm{~h}$-systolic BP and office of $154 \pm 19 \mathrm{mmHg}$ and $163 \pm 25 \mathrm{mmHg}$ respectively and receiving an average of 4.8 medications [113, 114]. In this subgroup, the BP fall was consistent across all followup time points, with an average decrease of BP of -11.6 $\mathrm{mmHg}$ at three year [114]. The BP lowering efficacy of RDN appears to be similar in patients with and without CKD. Kidney events and renal function were within the expected range for hypertensive patients without long-term safety concerns being observed, as confirmed also by a recent meta-analysis [115]. However, there was no evidence of a detrimental or positive effect on CKD progression. Yet, more clinical data, particularly on safety with concerns for process-associated endothelium damage, de novo renal artery stenosis, contrast induced nephropathy, are needed in order to establish this interventional treatment in the clinical algorithms for the management of HTA in CKD [108]. Indeed, a small study of 11 resistant hypertensive patients with moderateto-severe CKD using CO2 angiography instead of iodine based angiography, showed no significant changes in serum creatinine until 6 months and a trend of lowering proteinuria at 6 months [116]. Stabilizing and/or improving GFR after RDN was demonstrated in small studies including adults with different stages of CKD and refractory hypertension until 24-months post-RDN. However, in none of these studies a control arm was used [117-119]. Therefore, the nephroprotective effect of RDN remains to be demonstrated. This is also true for hard cardiovascular endpoints. In this 
respect, an ongoing randomized double blind, sham-controlled trial, the Renal Denervation- Chronic Kidney Disease (NCT04264403) may provide further insights regarding the magnitude of BP reduction and nephroprotection induced by RDN. Until further evidence for safety and efficacy, devicebased therapy of hypertension is not recommended for the routine treatment of HTA in patients with CKD.

\section{Conclusions}

Management of high BP in patients with CKD is multitasking; considering the complexity of the disease, the comorbidities and complications of renal disease, the high pill burden and the need for achieving optimal adherence, it represents a really challenge for all physicians.

Achieving at least the target of $<140 / 90 \mathrm{mmHg}$ in all CKD patients with implementation of lifestyle advices and starting with a RASi as first line treatment is almost uniformly accepted. When target is not reached, a stepwise approach adding CCB and/or diuretic, preferentially in a single pill combination is suggested, with the MR antagonist being kept for resistant hypertension (Fig. 2). A careful follow-up of renal function and electrolytes is mandatory with parallel avoidance of nephrotoxic drugs (e.g. NSAIDs), while exclusion of other causes of resistant hypertension should be considered when needed.
The recent development of SGLT2 inhibitors and finerenone, which provide additional renal and cardiovascular benefits on top of the classical pharmacological treatment of hypertension will change substantially our way to manage CKD patients with or without hypertension in the next decades. In the near future, clinical studies should provide additional information on how to integrate these new pharmacological or interventional treatments in the management of hypertensive patients with CKD. Indeed, there are still many unanswered questions, one of them being how could we optimize these new therapeutic approaches for example combining them, as these novel drugs can present potentially synergistic effects. Thus, in the FIGARO trial, $8 \%$ of patients receiving finerenone were also taking either a SGLT2 inhibitor or a GLP1 receptor agonist. Interestingly, the benefits of finerenone were greater among patients receiving simultaneously an SGLT2 inhibitor [76]. However, the number of patients using both drugs on of finerenone was small; hence additional studies are needed to confirm the potential benefits of combining finerenone and SGLT2 inhibitors in patients with diabetic nephropathy.

Taken all these new aspects together and considering the concept of personalized medicine (Fig. 2), our ability to improve the cardiovascular and renal prognosis of CKD patients with hypertension is much better now than it was in past decades and additional improvements are still to come.

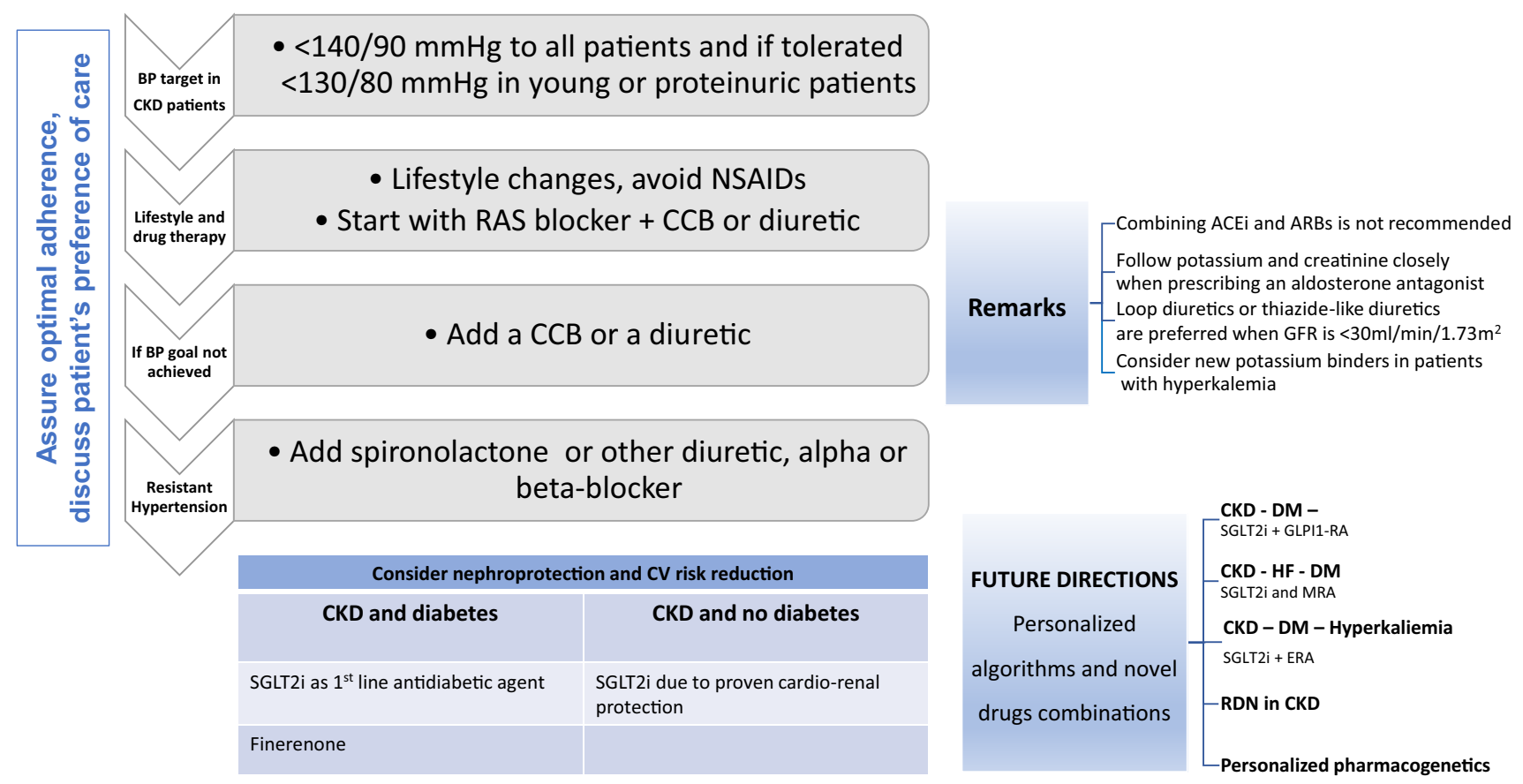

Fig. 2 Treatment strategy of hypertension in CKD and future directions. $R A S$ renin-angiotensin system, $C C B$ calcium channel blocker, $A C E i$ angiotensin converting enzyme inhibitor, $C K D$ chronic kidney disease, $D M$ diabetes mellitus, $S G L T 2 i$ sodium glucose transporter
2 inhibitors, GLP1-RA glucagon-like peptide-1 receptor agonist, $H F$ heart failure, $M R A$ mineral receptor antagonists, $R D N$ renal denervation 


\section{Declarations}

Conflicts of interest MB has received research grants and speaker fees from Servier, Menarini, Sanofi, Vifor Pharma, Idorsia, Boehringer Ingelheim, Actelion, Bayer. GW, EP and KD have no conflict of interest

Open Access This article is licensed under a Creative Commons Attribution-NonCommercial 4.0 International License, which permits any non-commercial use, sharing, adaptation, distribution and reproduction in any medium or format, as long as you give appropriate credit to the original author(s) and the source, provide a link to the Creative Commons licence, and indicate if changes were made. The images or other third party material in this article are included in the article's Creative Commons licence, unless indicated otherwise in a credit line to the material. If material is not included in the article's Creative Commons licence and your intended use is not permitted by statutory regulation or exceeds the permitted use, you will need to obtain permission directly from the copyright holder. To view a copy of this licence, visit http://creativecommons.org/licenses/by-nc/4.0/.

\section{References}

1. Collaborators GBDCoD. Global, regional, and national age-sex specific mortality for 264 causes of death, 1980-2016: a systematic analysis for the Global Burden of Disease Study 2016. Lancet. 2017;390(10100):1151-210

2. Hansrivijit P, Chen YJ, Lnu K, Trongtorsak A, Puthenpura MM, Thongprayoon $\mathrm{C}$, et al. Prediction of mortality among patients with chronic kidney disease: a systematic review. World J Nephrol. 2021;10(4):59-75

3. Levey AS, de Jong PE, Coresh J, El Nahas M, Astor BC, Matsushita $\mathrm{K}$, et al. The definition, classification, and prognosis of chronic kidney disease: a KDIGO controversies Conference report. Kidney Int. 2011;80(1):17-28.

4. Thomas MC, Cooper ME, Zimmet P. Changing epidemiology of type 2 diabetes mellitus and associated chronic kidney disease. Nat Rev Nephrol. 2016;12(2):73-81.

5. Nissenson AR, Collins AJ, Hurley J, Petersen H, Pereira BJG, Steinberg EP. Opportunities for improving the care of patients with chronic renal insufficiency: current practice patterns. J Am Soc Nephrol. 2001;12(8):1713-20.

6. Burnier M, Pruijm M, Wuerzner G, Santschi V. Drug adherence in chronic kidney diseases and dialysis. Nephrol Dial Transplant. 2015;30(1):39-44.

7. Hoerger TJ, Simpson SA, Yarnoff BO, Pavkov ME, Rios Burrows $\mathrm{N}$, Saydah SH, et al. The future burden of CKD in the United States: a simulation model for the CDC CKD initiative. Am J Kidney Dis. 2015;65(3):403-11.

8. Liu P, Quinn RR, Lam NN, Elliott MJ, Xu Y, James MT, et al. Accounting for age in the definition of chronic kidney disease. JAMA Intern Med. 2021;181(10):1359-66.

9. Visseren FLJ, Mach F, Smulders YM, Carballo D, Koskinas KC, Back M, et al. 2021 ESC Guidelines on cardiovascular disease prevention in clinical practice. Eur J Prev Cardiol. 2021;2:2.

10. Williams B, Mancia G, Spiering W, Agabiti Rosei E, Azizi M, Burnier M, et al. 2018 ESC/ESH Guidelines for the management of arterial hypertension. Eur Heart J. 2018;39(33):3021-104.

11. Vanholder R, Argiles A, Baurmeister U, Brunet P, Clark W, Cohen $\mathrm{G}$, et al. Uremic toxicity: present state of the art. Int $\mathrm{J}$ Artif Organs. 2001;24(10):695-725.

12. Manjunath G, Tighiouart H, Ibrahim H, MacLeod B, Salem DN, Griffith JL, et al. Level of kidney function as a risk factor for atherosclerotic cardiovascular outcomes in the community. J Am Coll Cardiol. 2003;41(1):47-55.

13. Tonelli M, Wiebe N, Culleton B, House A, Rabbat C, Fok M, et al. Chronic kidney disease and mortality risk: a systematic review. J Am Soc Nephrol. 2006;17(7):2034-47.

14. van der Velde M, Matsushita K, Coresh J, Astor BC, Woodward M, Levey A, et al. Lower estimated glomerular filtration rate and higher albuminuria are associated with all-cause and cardiovascular mortality. A collaborative meta-analysis of high-risk population cohorts. Kidney Int. 2011;79(12):1341-52.

15. Chronic Kidney Disease Prognosis C, Matsushita K, van der Velde M, Astor BC, Woodward M, Levey AS, et al. Association of estimated glomerular filtration rate and albuminuria with allcause and cardiovascular mortality in general population cohorts: a collaborative meta-analysis. Lancet. 2010;375(9731):2073-81.

16. Kidney Disease: Improving Global Outcomes Blood Pressure Work G. KDIGO 2021 Clinical Practice Guideline for the Management of Blood Pressure in Chronic Kidney Disease. Kidney Int. 2021;99(3S):S1-S87.

17. Unger T, Borghi C, Charchar F, Khan NA, Poulter NR, Prabhakaran D, et al. 2020 International society of hypertension global hypertension practice guidelines. Hypertension. 2020;75(6):1334-57.

18. Whelton PK, Carey RM, Aronow WS, Casey DE Jr, Collins KJ, Dennison Himmelfarb C, et al. 2017 ACC/AHA/AAPA/ ABC/ACPM/AGS/APhA/ASH/ASPC/NMA/PCNA guideline for the prevention, detection, evaluation, and management of high blood pressure in adults: executive summary: a report of the American College of Cardiology/American Heart Association Task Force on Clinical Practice Guidelines. Hypertension. 2018;71(6):1269-324.

19. Cheung AK, Chang TI, Cushman WC, Furth SL, Hou FF, Ix JH, et al. Executive summary of the KDIGO 2021 clinical practice guideline for the management of blood pressure in chronic kidney disease. Kidney Int. 2021;99(3):559-69.

20. Filipovsky J, Seidlerova J, Kratochvil Z, Karnosova P, Hronova M, Mayer O Jr. Automated compared to manual office blood pressure and to home blood pressure in hypertensive patients. Blood Press. 2016;25(4):228-34.

21. Group SR, Wright JT Jr, Williamson JD, Whelton PK, Snyder JK, Sink KM, et al. A randomized trial of intensive versus standard blood-pressure control. N Engl J Med. 2015;373(22):2103-16.

22. Plantinga LC, Miller ER 3rd, Stevens LA, Saran R, Messer K, Flowers N, et al. Blood pressure control among persons without and with chronic kidney disease: US trends and risk factors 1999-2006. Hypertension. 2009;54(1):47-56.

23. Fukuda M, Munemura M, Usami T, Nakao N, Takeuchi O, Kamiya Y, et al. Nocturnal blood pressure is elevated with natriuresis and proteinuria as renal function deteriorates in nephropathy. Kidney Int. 2004;65(2):621-5.

24. Kastarinen H, Vasunta RL, Ukkola O, Kesaniemi YA. Glomerular filtration rate is related to dipping pattern in ambulatory blood pressure monitoring - a cross-sectional population-based study. J Hum Hypertens. 2010;24(4):247-53.

25. Drawz PE, Alper AB, Anderson AH, Brecklin CS, Charleston J, Chen J, et al. Masked hypertension and elevated nighttime blood pressure in CKD: prevalence and association with target organ damage. Clin J Am Soc Nephrol. 2016;11(4):642-52.

26. Pogue V, Rahman M, Lipkowitz M, Toto R, Miller E, Faulkner $\mathrm{M}$, et al. Disparate estimates of hypertension control from ambulatory and clinic blood pressure measurements in hypertensive kidney disease. Hypertension. 2009;53(1):20-7.

27. Sinha AD, Agarwal R. The complex relationship between CKD and ambulatory blood pressure patterns. Adv Chronic Kidney Dis. 2015;22(2):102-7. 
28. Agarwal R, Pappas MK, Sinha AD. Masked uncontrolled hypertension in CKD. J Am Soc Nephrol. 2016;27(3):924-32.

29. Mwasongwe SE, Tanner RM, Poudel B, Pugliese DN, Young BA, Abdalla M, et al. Ambulatory blood pressure phenotypes in adults taking antihypertensive medication with and without CKD. Clin J Am Soc Nephrol. 2020;15(4):501-10.

30. Bangash F, Agarwal R. Masked hypertension and white-coat hypertension in chronic kidney disease: a meta-analysis. Clin J Am Soc Nephrol. 2009;4(3):656-64.

31. Tang H, Gong WY, Zhang QZ, Zhang J, Ye ZC, Peng H, et al. Prevalence, determinants, and clinical significance of masked hypertension and white-coat hypertension in patients with chronic kidney disease. Nephrology (Carlton). 2016;21(10):841-50.

32. Redon J, Plancha E, Swift PA, Pons S, Munoz J, Martinez F. Nocturnal blood pressure and progression to end-stage renal disease or death in nondiabetic chronic kidney disease stages 3 and 4. J Hypertens. 2010;28(3):602-7.

33. Davidson MB, Hix JK, Vidt DG, Brotman DJ. Association of impaired diurnal blood pressure variation with a subsequent decline in glomerular filtration rate. Arch Intern Med. 2006;166(8):846-52.

34. Agarwal R, Andersen MJ. Prognostic importance of clinic and home blood pressure recordings in patients with chronic kidney disease. Kidney Int. 2006;69(2):406-11.

35. Cianciaruso B, Bellizzi V, Minutolo R, Colucci G, Bisesti V, Russo D, et al. Renal adaptation to dietary sodium restriction in moderate renal failure resulting from chronic glomerular disease. J Am Soc Nephrol. 1996;7(2):306-13.

36. Burnier M, Coltamai L, Maillard M, Bochud M. Renal sodium handling and nighttime blood pressure. Semin Nephrol. 2007;27(5):565-71.

37. Bigazzi R, Bianchi S, Baldari D, Sgherri G, Baldari G, Campese VM. Microalbuminuria in salt-sensitive patients. A marker for renal and cardiovascular risk factors. Hypertension. 1994;23(2):195-9.

38. McMahon EJ, Campbell KL, Bauer JD, Mudge DW. Altered dietary salt intake for people with chronic kidney disease. Cochrane Database Syst Rev. 2015;2:CD010070.

39. Suckling RJ, He FJ, Macgregor GA. Altered dietary salt intake for preventing and treating diabetic kidney disease. Cochrane Database Syst Rev. 2010;12:CD006763.

40. Burnier M. Sodium intake and progression of chronic kidney disease-has the time finally come to do the impossible: a prospective randomized controlled trial? Nephrol Dial Transplant. 2021;36(3):381-4.

41. Marklund M, Singh G, Greer R, Cudhea F, Matsushita K, Micha R, et al. Estimated population wide benefits and risks in China of lowering sodium through potassium enriched salt substitution: modelling study. BMJ. 2020;369:824.

42. Neal B, Wu Y, Feng X, Zhang R, Zhang Y, Shi J, et al. Effect of salt substitution on cardiovascular events and death. N Engl J Med. 2021;385(12):1067-77.

43. Lambers Heerspink HJ, Holtkamp FA, Parving HH, Navis GJ, Lewis JB, Ritz E, et al. Moderation of dietary sodium potentiates the renal and cardiovascular protective effects of angiotensin receptor blockers. Kidney Int. 2012;82(3):330-7.

44. Wright JT Jr, Bakris G, Greene T, Agodoa LY, Appel LJ, Charleston J, et al. Effect of blood pressure lowering and antihypertensive drug class on progression of hypertensive kidney disease: results from the AASK trial. JAMA. 2002;288(19):2421-31.

45. Randomised placebo-controlled trial of effect of ramipril on decline in glomerular filtration rate and risk of terminal renal failure in proteinuric, non-diabetic nephropathy. The GISEN
Group (Gruppo Italiano di Studi Epidemiologici in Nefrologia). Lancet. 1997;349(9069):1857-63.

46. Brenner BM, Cooper ME, de Zeeuw D, Keane WF, Mitch WE, Parving HH, et al. Effects of losartan on renal and cardiovascular outcomes in patients with type 2 diabetes and nephropathy. $\mathrm{N}$ Engl J Med. 2001;345(12):861-9.

47. Lewis EJ, Hunsicker LG, Clarke WR, Berl T, Pohl MA, Lewis $\mathrm{JB}$, et al. Renoprotective effect of the angiotensin-receptor antagonist irbesartan in patients with nephropathy due to type 2 diabetes. N Engl J Med. 2001;345(12):851-60.

48. Schmidt M, Mansfield KE, Bhaskaran K, Nitsch D, Sorensen HT, Smeeth L, et al. Serum creatinine elevation after renin-angiotensin system blockade and long term cardiorenal risks: cohort study. BMJ. 2017;356:791.

49. Ahmed A, Jorna T, Bhandari S. Should we STOP angiotensin converting enzyme inhibitors/angiotensin receptor blockers in advanced kidney disease? Nephron. 2016;133(3):147-58.

50. Burnier M. Renin-angiotensin system blockade in advanced kidney disease: stop or continue? Kidney Med. 2020;2(3):231-4.

51. Fu EL, Evans M, Clase CM, Tomlinson LA, van Diepen M, Dekker FW, et al. Stopping renin-angiotensin system inhibitors in patients with advanced CKD and risk of adverse outcomes: a nationwide study. J Am Soc Nephrol. 2021;32(2):424-35.

52. Walther CP, Winkelmayer WC, Richardson PA, Virani SS, Navaneethan SD. Renin-angiotensin system blocker discontinuation and adverse outcomes in chronic kidney disease. Nephrol Dial Transplant. 2021;36(10):1893-9.

53. Weir MR, Bakris GL, Bushinsky DA, Mayo MR, Garza D, Stasiv Y, et al. Patiromer in patients with kidney disease and hyperkalemia receiving RAAS inhibitors. $N$ Engl J Med. 2015;372(3):211-21.

54. Bakris GL, Pitt B, Weir MR, Freeman MW, Mayo MR, Garza D, et al. Effect of patiromer on serum potassium level in patients with hyperkalemia and diabetic kidney disease: the AMETHYST-DN randomized clinical trial. JAMA. 2015;314(2):151-61.

55. Strauss MH, Hall AS. Angiotensin receptor blockers may increase risk of myocardial infarction: unraveling the ARB-MI paradox. Circulation. 2006;114(8):838-54.

56. Potier L, Roussel R, Elbez Y, Marre M, Zeymer U, Reid $\mathrm{CM}$, et al. Angiotensin-converting enzyme inhibitors and angiotensin receptor blockers in high vascular risk. Heart. 2017;103(17):1339-46.

57. Reboldi G, Angeli F, Cavallini C, Gentile G, Mancia G, Verdecchia P. Comparison between angiotensin-converting enzyme inhibitors and angiotensin receptor blockers on the risk of myocardial infarction, stroke and death: a meta-analysis. J Hypertens. 2008;26(7):1282-9.

58. Chen R, Suchard MA, Krumholz HM, Schuemie MJ, Shea S, Duke J, et al. Comparative first-line effectiveness and safety of ACE (angiotensin-converting enzyme) inhibitors and angiotensin receptor blockers: a multinational cohort study. Hypertension. 2021;78(3):591-603.

59. Bakris GL, Sarafidis PA, Weir MR, Dahlof B, Pitt B, Jamerson K, et al. Renal outcomes with different fixed-dose combination therapies in patients with hypertension at high risk for cardiovascular events (ACCOMPLISH): a prespecified secondary analysis of a randomised controlled trial. Lancet. 2010;375(9721):1173-81.

60. Jamerson K, Weber MA, Bakris GL, Dahlof B, Pitt B, Shi V, et al. Benazepril plus amlodipine or hydrochlorothiazide for hypertension in high-risk patients. N Engl J Med. 2008;359(23):2417-28.

61. Hung SC, Kuo KL, Peng CH, Wu CH, Lien YC, Wang YC, et al. Volume overload correlates with cardiovascular risk factors in patients with chronic kidney disease. Kidney Int. 2014;85(3):703-9. 
62. Dussol B, Moussi-Frances J, Morange S, Somma-Delpero C, Mundler O, Berland Y. A pilot study comparing furosemide and hydrochlorothiazide in patients with hypertension and stage 4 or 5 chronic kidney disease. J Clin Hypertens (Greenwich). 2012;14(1):32-7.

63. Dorsch MP, Gillespie BW, Erickson SR, Bleske BE, Weder AB. Chlorthalidone reduces cardiovascular events compared with hydrochlorothiazide: a retrospective cohort analysis. Hypertension. 2011;57(4):689-94.

64. Agarwal R, Cramer AE, Balmes-Fenwick M, Sinha AD, Ouyang F, Tu W. Design and baseline characteristics of the chlorthalidone in chronic kidney disease (CLICK) trial. Am J Nephrol. 2020;51(7):542-52.

65. Ecder T, Edelstein CL, Fick-Brosnahan GM, Johnson AM, Chapman AB, Gabow PA, et al. Diuretics versus angiotensin-converting enzyme inhibitors in autosomal dominant polycystic kidney disease. Am J Nephrol. 2001;21(2):98-103.

66. Converse RL Jr, Jacobsen TN, Toto RD, Jost CM, Cosentino F, Fouad-Tarazi F, et al. Sympathetic overactivity in patients with chronic renal failure. N Engl J Med. 1992;327(27):1912-8.

67. Bangalore S, Messerli FH, Kostis JB, Pepine CJ. Cardiovascular protection using beta-blockers: a critical review of the evidence. J Am Coll Cardiol. 2007;50(7):563-72.

68. Williams B, MacDonald TM, Morant S, Webb DJ, Sever P, McInnes G, et al. Spironolactone versus placebo, bisoprolol, and doxazosin to determine the optimal treatment for drug-resistant hypertension (PATHWAY-2): a randomised, double-blind, crossover trial. Lancet. 2015;386(10008):2059-68.

69. Chung EY, Ruospo M, Natale P, Bolignano D, Navaneethan $\mathrm{SD}$, Palmer SC, et al. Aldosterone antagonists in addition to renin angiotensin system antagonists for preventing the progression of chronic kidney disease. Cochrane Database Syst Rev. 2020;10:CD007004.

70. Rossier MF. The cardiac mineralocorticoid receptor (MR): a therapeutic target against ventricular arrhythmias. Front Endocrinol (Lausanne). 2021;12:694758.

71. Bauersachs J, Jaisser F, Toto R. Mineralocorticoid receptor activation and mineralocorticoid receptor antagonist treatment in cardiac and renal diseases. Hypertension. 2015;65(2):257-63.

72. Alexandrou ME, Papagianni A, Tsapas A, Loutradis C, Boutou A, Piperidou A, et al. Effects of mineralocorticoid receptor antagonists in proteinuric kidney disease: a systematic review and meta-analysis of randomized controlled trials. J Hypertens. 2019;37(12):2307-24.

73. Ortiz A, Ferro CJ, Balafa O, Burnier M, Ekart R, Halimi JM, et al. Mineralocorticoid receptor antagonists for nephroprotection and cardioprotection in patients with diabetes mellitus and chronic kidney disease. Nephrol Dial Transplant. 2021;2:2.

74. Agarwal R, Rossignol P, Romero A, Garza D, Mayo MR, Warren $\mathrm{S}$, et al. Patiromer versus placebo to enable spironolactone use in patients with resistant hypertension and chronic kidney disease (AMBER): a phase 2, randomised, double-blind, placebocontrolled trial. Lancet. 2019;394(10208):1540-50.

75. Bakris GL, Agarwal R, Anker SD, Pitt B, Ruilope LM, Rossing $\mathrm{P}$, et al. Effect of finerenone on chronic kidney disease outcomes in type 2 diabetes. N Engl J Med. 2020;383(23):2219-29.

76. Pitt B, Filippatos G, Agarwal R, Anker SD, Bakris GL, Rossing $\mathrm{P}$, et al. Cardiovascular events with finerenone in kidney disease and type 2 diabetes. N Engl J Med. 2021;2:2.

77. Filippatos G, Anker SD, Agarwal R, Pitt B, Ruilope LM, Rossing $\mathrm{P}$, et al. Finerenone and cardiovascular outcomes in patients with chronic kidney disease and type 2 diabetes. Circulation. 2021;143(6):540-52.

78. Juurlink DN, Mamdani MM, Lee DS, Kopp A, Austin PC, Laupacis A, et al. Rates of hyperkalemia after publication of the randomized aldactone evaluation study. N Engl J Med. 2004;351(6):543-51.

79. Ito S, Itoh H, Rakugi H, Okuda Y, Iijima S. Antihypertensive effects and safety of esaxerenone in patients with moderate kidney dysfunction. Hypertens Res. 2021;44(5):489-97.

80. Duggan S. Esaxerenone: first global approval. Drugs. 2019;79(4):477-81.

81. Ito S, Kashihara N, Shikata K, Nangaku M, Wada T, Okuda Y, et al. Esaxerenone (CS-3150) in patients with type 2 diabetes and microalbuminuria (ESAX-DN): phase 3 randomized controlled clinical trial. Clin J Am Soc Nephrol. 2020;15(12):1715-27.

82. Mancia G, Cannon CP, Tikkanen I, Zeller C, Ley L, Woerle HJ, et al. Impact of empagliflozin on blood pressure in patients with type 2 diabetes mellitus and hypertension by background antihypertensive medication. Hypertension. 2016;68(6):1355-64.

83. Dekkers CCJ, Wheeler DC, Sjostrom CD, Stefansson BV, Cain V, Heerspink HJL. Effects of the sodium-glucose cotransporter 2 inhibitor dapagliflozin in patients with type 2 diabetes and Stages 3b-4 chronic kidney disease. Nephrol Dial Transplant. 2018;33(11):2005-11.

84. Georgianos PI, Agarwal R. Ambulatory Blood Pressure Reduction with SGLT-2 inhibitors: dose-response meta-analysis and comparative evaluation with low-dose hydrochlorothiazide. Diabetes Care. 2019;42(4):693-700.

85. Heerspink HJL, Stefánsson BV, Correa-Rotter R, Chertow GM, Greene T, Hou F-F, et al. Dapagliflozin in patients with chronic kidney disease. N Engl J Med. 2020;383(15):1436-46.

86. Mann JFE, Orsted DD, Brown-Frandsen K, Marso SP, Poulter NR, Rasmussen S, et al. Liraglutide and renal outcomes in type 2 diabetes. N Engl J Med. 2017;377(9):839-48.

87. Kristensen SL, Rorth R, Jhund PS, Docherty KF, Sattar N, Preiss D, et al. Cardiovascular, mortality, and kidney outcomes with GLP-1 receptor agonists in patients with type 2 diabetes: a systematic review and meta-analysis of cardiovascular outcome trials. Lancet Diabetes Endocrinol. 2019;7(10):776-85.

88. American DA. 9. Pharmacologic approaches to glycemic treatment: standards of medical care in diabetes-2020. Diabetes Care. 2020;43(1):S98-110.

89. Lovshin JA, Barnie A, DeAlmeida A, Logan A, Zinman B, Drucker DJ. Liraglutide promotes natriuresis but does not increase circulating levels of atrial natriuretic peptide in hypertensive subjects with type 2 diabetes. Diabetes Care. 2015;38(1):132-9.

90. Yamada T, Wakabayashi M, Bhalla A, Chopra N, Miyashita $\mathrm{H}$, Mikami T, et al. Cardiovascular and renal outcomes with SGLT-2 inhibitors versus GLP-1 receptor agonists in patients with type 2 diabetes mellitus and chronic kidney disease: a systematic review and network meta-analysis. Cardiovasc Diabetol. 2021;20(1):14.

91. Burnier M. Update on endothelin receptor antagonists in hypertension. Curr Hypertens Rep. 2018;20(6):51.

92. Yamamoto T, Suzuki H, Kubo Y, Matsumoto A, Uemura H. Endothelin A receptor-like immunoreactivity on the basal infoldings of rat renal tubules and collecting ducts. Arch Histol Cytol. 2008;71(2):77-87.

93. Kohan DE, Barton M. Endothelin and endothelin antagonists in chronic kidney disease. Kidney Int. 2014;86(5):896-904.

94. Kohan DE, Rossi NF, Inscho EW, Pollock DM. Regulation of blood pressure and salt homeostasis by endothelin. Physiol Rev. 2011;91(1):1-77.

95. Komers R, Plotkin H. Dual inhibition of renin-angiotensinaldosterone system and endothelin-1 in treatment of chronic kidney disease. Am J Physiol Regul Integr Comp Physiol. 2016;310(10):R877-84.

96. Provenzano M, Andreucci M, Garofalo C, Minutolo R, Serra $\mathrm{R}$, De Nicola L. Selective endothelin A receptor antagonism in 
patients with proteinuric chronic kidney disease. Expert Opin Investig Drugs. 2021;30(3):253-62.

97. Dhaun N, MacIntyre IM, Kerr D, Melville V, Johnston NR, Haughie $\mathrm{S}$, et al. Selective endothelin-A receptor antagonism reduces proteinuria, blood pressure, and arterial stiffness in chronic proteinuric kidney disease. Hypertension. 2011;57(4):772-9.

98. Trachtman H, Nelson P, Adler S, Campbell KN, Chaudhuri A, Derebail VK, et al. DUET: a phase 2 study evaluating the efficacy and safety of sparsentan in patients with FSGS. J Am Soc Nephrol. 2018;29(11):2745-54.

99. Kohan DE, Pritchett Y, Molitch M, Wen S, Garimella T, Audhya $\mathrm{P}$, et al. Addition of atrasentan to renin-angiotensin system blockade reduces albuminuria in diabetic nephropathy. J Am Soc Nephrol. 2011;22(4):763-72.

100. Heerspink HJL, Parving HH, Andress DL, Bakris G, CorreaRotter R, Hou FF, et al. Atrasentan and renal events in patients with type 2 diabetes and chronic kidney disease (SONAR): a double-blind, randomised, placebo-controlled trial. Lancet. 2019;393(10184):1937-47.

101. Dhaun N, Macintyre IM, Melville V, Lilitkarntakul P, Johnston NR, Goddard J, et al. Blood pressure-independent reduction in proteinuria and arterial stiffness after acute endothelin-a receptor antagonism in chronic kidney disease. Hypertension. 2009;54(1):113-9.

102. Bakris GL, Lindholm LH, Black HR, Krum H, Linas S, Linseman JV, et al. Divergent results using clinic and ambulatory blood pressures: report of a darusentan-resistant hypertension trial. Hypertension. 2010;56(5):824-30.

103. Barratt J, Rovin B, Diva U, Mercer A, Komers R, Group PSD. Implementing the kidney health initiative surrogate efficacy endpoint in patients with IgA nephropathy (the PROTECT Trial). Kidney Int Rep. 2019;4(11):1633-7.

104. Komers R, Diva U, Inrig JK, Loewen A, Trachtman H, Rote WE. Study design of the phase 3 sparsentan versus irbesartan (DUPLEX) study in patients with focal segmental glomerulosclerosis. Kidney Int Rep. 2020;5(4):494-502.

105. Lobo MD, Sobotka PA, Pathak A. Interventional procedures and future drug therapy for hypertension. Eur Heart J. 2017;38(15):1101-11.

106. Weber MA, Mahfoud F, Schmieder RE, Kandzari DE, Tsioufis $\mathrm{KP}$, Townsend RR, et al. Renal denervation for treating hypertension: current scientific and clinical evidence. JACC Cardiovasc Interv. 2019;12(12):1095-105.

107. Schneider MP, Hilgers KF, Schmid M, Hubner S, Nadal J, Seitz $\mathrm{D}$, et al. Blood pressure control in chronic kidney disease: A cross-sectional analysis from the German Chronic Kidney Disease (GCKD) study. PLoS ONE. 2018;13(8):e0202604
108. Schmieder RE. Renal denervation: where do we stand and what is the relevance to the nephrologist? Nephrol Dial Transplant. 2020;2:2.

109. Pappaccogli M, Covella M, Berra E, Fulcheri C, Di Monaco $\mathrm{S}$, Perlo E, et al. Effectiveness of renal denervation in resistant hypertension: a meta-analysis of 11 controlled studies. High Blood Press Cardiovasc Prev. 2018;25(2):167-76.

110. Sardar P, Bhatt DL, Kirtane AJ, Kennedy KF, Chatterjee S, Giri $\mathrm{J}$, et al. Sham-controlled randomized trials of catheter-based renal denervation in patients with hypertension. J Am Coll Cardiol. 2019;73(13):1633-42.

111. Bohm M, Kario K, Kandzari DE, Mahfoud F, Weber MA, Schmieder RE, et al. Efficacy of catheter-based renal denervation in the absence of antihypertensive medications (SPYRAL HTNOFF MED Pivotal): a multicentre, randomised, sham-controlled trial. Lancet. 2020;395(10234):1444-51.

112. Azizi M, Schmieder RE, Mahfoud F, Weber MA, Daemen J, Davies J, et al. Endovascular ultrasound renal denervation to treat hypertension (RADIANCE-HTN SOLO): a multicentre, international, single-blind, randomised, sham-controlled trial. Lancet. 2018;391(10137):2335-45.

113. Mahfoud F, Bohm M, Schmieder R, Narkiewicz K, Ewen S, Ruilope L, et al. Effects of renal denervation on kidney function and long-term outcomes: 3-year follow-up from the global SYMPLICITY registry. Eur Heart J. 2019;40(42):3474-82.

114. Mahfoud F, Mancia G, Schmieder R, Narkiewicz K, Ruilope L, Schlaich M, et al. Renal denervation in high-risk patients with hypertension. J Am Coll Cardiol. 2020;75(23):2879-88.

115. Townsend RR, Walton A, Hettrick DA, Hickey GL, Weil J, Sharp ASP, et al. Review and meta-analysis of renal artery damage following percutaneous renal denervation with radiofrequency renal artery ablation. EuroIntervention. 2020;16(1):89-96.

116. Hameed MA, Freedman JS, Watkin R, Ganeshan A, Dasgupta I. Renal denervation using carbon dioxide renal angiography in patients with uncontrolled hypertension and moderate to severe chronic kidney disease. Clin Kidney J. 2017;10(6):778-82.

117. Ott C, Mahfoud F, Schmid A, Toennes SW, Ewen S, Ditting T, et al. Renal denervation preserves renal function in patients with chronic kidney disease and resistant hypertension. J Hypertens. 2015;33(6):1261-6.

118. Kiuchi MG, Chen S. Improvement of renal function after renal sympathetic denervation in CKD patients with controlled vs uncontrolled hypertension. Int J Cardiol. 2016;223:494-6.

119. Hering D, Marusic P, Duval J, Sata Y, Head GA, Denton KM, et al. Effect of renal denervation on kidney function in patients with chronic kidney disease. Int J Cardiol. 2017;232:93-7. 